\title{
The effect of tourniquet use on hidden blood loss in total knee arthroplasty
}

\author{
Bin Li • Yu Wen • Haishan Wu • Qirong Qian • \\ Xiangbo Lin $\cdot$ Hui Zhao
}

Received: 2 July 2008 /Revised: 20 July 2008 / Accepted: 21 July 2008 /Published online: 27 August 2008

(C) Springer-Verlag 2008

\begin{abstract}
The objective of this study was to examine the characteristics of hidden blood loss and assess the effects of using a tourniquet on postoperative hidden loss in patients undergoing primary total knee arthroplasty. Eighty patients were randomised into two groups: one group underwent operation with a tourniquet and one without. Operating time, perioperative blood loss, hidden blood loss, free haemoglobin, swelling, ecchymosis, straight leg raising action and knee flexion were measured. There were significant differences in the hidden blood loss, free haemoglobin, postoperative swelling, extent of ecchymosis, straight leg raising and postoperative knee flexion in the early period after operation between the two groups. Our results indicate that knee arthroplasty operations with a tourniquet might promote postoperative hidden blood loss and hinder patients' in early postoperative rehabilitation exercises.
\end{abstract}

Résumé L'objectif de l'étude est de déterminer les caractéristiques des pertes sanguines occultes et les effets de l'utilisation du garrot sur ces pertes sanguines dans les prothèses totales du genou primaires. Matériel et méthode: les patients ont été randomisés en deux groupes, un groupe a été opéré sous garrot et un groupe sans garrot. Le temps opératoire, les pertes sanguines péri-opératoires et occultes,

B. Li $\cdot$ H. Wu $(\bowtie) \cdot$ Q. Qian $\cdot$ X. Lin $\cdot$ H. Zhao

Department of Orthopaedic Surgery, Arthritis Institute,

Changzheng Hospital, Second Military Medical University,

Shanghai 200003, People's Republic of China

e-mail: surgeon_li@126.com

B. $\mathrm{Li}$

e-mail: wylb7475@163.com

Y. Wen

Department of Human Anatomy, College of Basic Medical Sciences, Second Military Medical University, Shanghai, People's Republic of China le taux d'hémoglobine, l'hématome, l'ecchymose, la possibilité d'extension active et de flexion du genou ont été mesurés. Résultats: il y a une différence significative sur les pertes sanguines occultes, le taux d'hémoglobine, les douleurs post-opératoires, les ecchymoses, l'élévation active de la jambe et la flexion du genou post-opératoire. En conclusion, nos résultats montrent que la prothèse totale $\mathrm{du}$ genou avec garrot, peut entraîner des pertes de sang occultes chez les patients notamment en cours de la rééducation post-opératoire.

\section{Introduction}

Blood loss following total knee arthroplasty (TKA) owing to extensive soft tissue release and bone cuts may result in significant anaemia and prolonged postoperative recovery [5]. Sehat et al. [19] reported that the total blood loss included the visible blood loss and the hidden blood loss. Following TKA, patients are frequently found to have a lower postoperative haemoglobin $(\mathrm{Hb})$ than anticipated, indicating that the hidden blood loss accounts for a significant proportion of the total blood loss. It could be between 50 and 38\%, according to the reports of Sehat et al. [19] and Prasad et al. [16], respectively, which show that the total blood loss should be considered when judging the extent of anaemia and determining the possibility of blood transfusion. To minimise blood loss, orthopaedic surgeons are accustomed to using a tourniquet in TKA, which could certainly reduce the intraoperative blood loss. But there are two different viewpoints about the effect of the tourniquet on the total blood loss: Salam et al. [1] and Tetro et al. [21] reported that using a tourniquet in TKA could reduce the total blood loss, while Harvey et al. [9], Wakankar et al. [24] and Vandenbussche et al. [23] had the contrary viewpoint. Meanwhile, the effect of the tourniquet on the hidden loss 
requires further study. We carried out a prospective, randomised study to approach the characteristics of hidden blood loss and assess the effects of using a tourniquet on postoperative hidden loss for primary TKA.

\section{Patients and methods}

\section{Patient data}

A prospective study was conducted for an eight-month period starting in August 2007 involving all patients who underwent primary TKA performed in our institution. The approval of the Institutional Review Board and informed consent from all participants were obtained. Eighty consecutive patients suffering from primary osteoarthritis (OA) and rheumatoid arthritis (RA) were recruited into the study. Exclusion criteria were specified as follows: bilateral TKA either simultaneously or staged at less than three-month intervals, diabetes, haemostatic defect, a history of peripheral vascular disease, presence of malignant tumour, preoperative level of $\mathrm{Hb}$ less than $10 \mathrm{~g} / 1$ and previous thromboembolism.

Random assignment was accomplished by using a random numbers list and assigning the random numbers to patients as they entered this study. Equal numbers of patients were assigned to group A, with tourniquet in TKA, and group B, without tourniquet in TKA. The final result of this randomisation was to have 40 patients in each of the groups. Neither patients nor nurses were informed as to whether or not a tourniquet was used. The patients in the two groups were well matched for age, gender, body mass index (BMI), aetiology, preoperative $\mathrm{Hb}$ and haematocrit (Hct) values, preoperative circumference length through the superior patellar pole and range of motion of the knee (Table 1).

\section{Surgical technique}

Standard techniques were used in all of the cases. The type of anaesthesia was chosen depending on the patients' needs. All procedures were performed by four similar staff surgeons. The implant used was the type of posterior cruciate ligament-substituting total knee prosthetic components (Genesis II, Smith \& Nephew Inc., Memphis, TN, USA). A midvastus approach was used through an anterior midline skin incision. Bone cuts and soft tissue balancing were done in the same sequence. The patella was not replaced in either group. The patellar was reshaped to match the shape of the femoral component trochlea better and the soft tissue around the patellar was cauterised with an electric scalpel to partly destroy the innervation of the patellar. To reduce the blood loss from the femoral canal an intramedullary plug with bone grafts was used before closure of the wound. In group A the tourniquet was inflated to $100 \mathrm{mmHg}$ above the systolic blood pressure after the leg was elevated and exsanguinated, and deflation was performed after the wound was closed and the compressive dressing applied. The tourniquet was not used in group B and the active bleeding points were promptly sealed with electric coagulation. Three grams of hemostatic powder (Arista, Medafor, Minneapolis, MN, USA) were steadily sprinkled on the wound surface before incision closure in both groups. Then the knee was placed in a compressive dressing following the application of a wool and crepe bandage to the limb in both groups. None of the patients were transfused during the operation. The transfusion trigger was a haemoglobin level less than $9 \mathrm{~g} / \mathrm{dl}$ measured at the 24th postoperative hour. No drains were used in the wounds.

\section{Postoperative management}

A uniform perioperative regimen was used in all of the cases. Antibiotic treatment with second-generation cephalosporin was infused intravenously (one dose preoperatively and for the next 2 days). The quantity of saline transfused intravenously within $24 \mathrm{~h}$ postoperatively was $2,500 \sim 3,000 \mathrm{ml}$. Every patient was evaluated to decide whether blood transfusion was needed according to the result of the
Table 1 Patient characteristics for the two groups (mean $\pm \mathrm{SD}$ or number)

\begin{tabular}{llll}
\hline & Group A $(n=40)$ & Group B $(n=40)$ & $P$ value \\
\hline Sex( F/M) & $29 / 11$ & $27 / 13$ & $\mathrm{x}^{2}, P=0.63$ \\
Age (years) & $71 \pm 6$ & $70 \pm 7$ & $t$-test, $P=0.24$ \\
BMI (kg/m $\left.{ }^{2}\right)$ & $27.3 \pm 6.3$ & $26.8 \pm 5.1$ & $t$-test, $P=0.17$ \\
Aetiology (OA/RA) & $33 / 7$ & $32 / 8$ & $\mathrm{x}^{2}, P=0.78$ \\
Preoperative Hb (g/l) & $133 \pm 11.7$ & $135 \pm 10.9$ & $t$-test, $P=0.53$ \\
Preoperative Hct (\%) & $42.4 \pm 5.3$ & $43.1 \pm 4.3$ & $t$-test, $P=0.52$ \\
Preoperative circumference & $36.4 \pm 1.4$ & $36.9 \pm 1.5$ & $t$-test, $P=0.05$ \\
$\quad$ length of the knee (cm) & & & \\
Preoperative range of motion $\left({ }^{\circ}\right)$ & $91 \pm 16$ & $92 \pm 13$ & $t$-test, $P=0.67$ \\
Anaesthesia (general/spinal) & $10 / 30$ & $12 / 28$ & $\mathrm{x}^{2}, P=0.62$ \\
Operating time (min) & $73 \pm 19$ & $82 \pm 15$ & $t$-test, $P=0.06$ \\
& & & \\
\hline
\end{tabular}


haemoglobin level measured at the 24th postoperative hour. Thus, the patients' haematocrit levels were well matched, not being lowered due to saline infusion or increased because of blood transfusion. All patients received standard thromboprophylaxis in the form of administration of low molecular weight heparin, pneumatic venous compression pumps and early mobilisation. The wound dressing was changed when soaked or bandaged so tightly as to hinder the blood circulation of the extremity. The affected limb was elevated to exceed the heart level. Ice bags were placed around the affected knees. Continuous passive movement was not used. Active isometric quadriceps, initiative straight leg raising and extending-flexing motion was encouraged just after operation, and walking with part weight-bearing was permitted 24 hours postoperatively under the supervision of a physiotherapist. The study data were documented by a surgeon who did not attend the operation.

\section{Outcome assessment}

Research indexes included operating time, intraoperative blood loss (IBL), postoperative wound blood loss (PWBL), calculated total blood loss (CBL), hidden blood loss (HBL), free haemoglobin level measured at the 24th postoperative hour, circumference length of the knee, the scope of ecchymosis calculated by the palm method, range of active knee flexion on the first, third and seventh postoperative days and the number of people who could conduct straight leg raising more than $60^{\circ}$.

- IBL: assessed by adding the amount of the volume in suction bottles after reduction of wound irrigation fluid and the net blood weight of the sponges used during the procedure.

- PWBL: soaked dressings were weighed and converted to volume. Due to evaporation from the soaked dressings before changing, there was an error between calculated volume and actual volume. So we increased the thickness of the dressings and the frequency of changing.

- CBL: calculated using the formula reported by Nadler et al. [13] and Gross [8]. The Hct value used in the formula was measured at the 24th postoperative hour.
- HBL: calculated by subtracting the IBL and the PWBL from the CBL.

- Circumference length of the knee: on postoperative days three and 14 the circumference length of the knee was measured through the superior patellar pole and the increased rate compared with the preoperative result was calculated.

\section{Statistical analysis}

Statistical analysis was performed with SPSS 11.0 software for Windows. Continuous data with normal distribution were expressed as means ( \pm standard deviation) and nonnormal distribution as media (range). A chi-square test was used for the comparison of nominal data and an unpaired Student's $t$-test was used for comparisons of continuous data when the data appeared to be approximately normally distributed. The Wilcoxon test was used for data where the assumption of normality did not hold. Differences at a level of $P<0.05$ were considered statistically significant.

\section{Results}

The results are shown in Table 2. There was a significant difference in the intraoperative blood loss between the two groups $(P=0.00)$. But in group $\mathrm{B}$, the absence of a tourniquet did not pose any problem, particularly in preparing the bone surfaces for cementing. The postoperative wound blood loss, the hidden blood loss and the calculated total blood loss were significantly greater in group A than in group B $(P=0.02$, 0.01 and 0.04 , respectively). The hidden loss as percentage of calculated total blood loss was $56 \%$ in group A and $42 \%$ in group B. There was a significance difference in the ratio.

As shown in Table 3, there was a significant difference in the free haemoglobin level between the two groups $(P=$ 0.00 ), which meant that the extent of haemocytolysis was more serious in group A than in group B. Knee measurements for swelling at three days and 14 days showed a significant difference $(P=0.00$ and 0.01 , respectively). Meanwhile, the scope of ecchymosis was larger in group A than in group $\mathrm{B}(P=0.00)$. The two sets of results

Table 2 Details of the blood loss

\begin{tabular}{llll}
\hline & Group A $(n=40)$ & Group B $(n=40)$ & $P$ value \\
\hline Intraoperative blood loss $(\mathrm{ml})($ mean $\pm \mathrm{SD})$ & $317 \pm 72$ & $469 \pm 44$ & $t$-test, $P=0.00$ \\
Postoperative wound blood loss $(\mathrm{ml})($ media, range) & $237(70-690)$ & $139(50-440)$ & Wilcoxon test, $P=0.02$ \\
Calculated total blood loss $(\mathrm{ml})($ mean $\pm \mathrm{SD})$ & $1,298 \pm 285$ & $1,117 \pm 221$ & $t$-test, $P=0.04$ \\
Hidden blood loss $(\mathrm{ml})($ media, range) & $701(568-946)$ & $589(458-775)$ & Wilcoxon test, $P=0.01$ \\
Hidden loss as ratio of calculated total blood loss (mean $\pm \mathrm{SD})$ & $0.56 \pm 0.05$ & $0.42 \pm 0.04$ & $t$-test, $P=0.00$ \\
\hline
\end{tabular}


Table 3 Details of the postoperative changes in both groups (mean $\pm \mathrm{SD}$ or number)

\begin{tabular}{|c|c|c|c|}
\hline & Group A $(n=40)$ & Group B $(n=40)$ & $P$ value \\
\hline \multicolumn{4}{|c|}{ Free haemoglobin concentration (mg/l) } \\
\hline & $173.5 \pm 76.3$ & $58.4 \pm 29.1$ & $t$-test, $P=0.00$ \\
\hline \multicolumn{4}{|c|}{ Increasing rate of circumference length of the knee (\%) } \\
\hline 3 days & $7.3 \pm 2.0$ & $5.7 \pm 2.6$ & $t$-test, $P=0.00$ \\
\hline 14 days & $6.2 \pm 1.8$ & $5.0 \pm 2.3$ & $t$-test, $P=0.01$ \\
\hline \multicolumn{4}{|c|}{ Scope of ecchymosis $(\%)$} \\
\hline & $2.4 \pm 0.7$ & $0.9 \pm 0.3$ & $t$-test, $P=0.00$ \\
\hline \multicolumn{4}{|c|}{ Range of active knee flexion $\left({ }^{\circ}\right)$} \\
\hline 1 day & $30 \pm 12$ & $44 \pm 13$ & $t$-test, $P=0.00$ \\
\hline 3 days & $47 \pm 11$ & $57 \pm 18$ & $t$-test, $P=0.02$ \\
\hline 7 days & $73 \pm 15$ & $75 \pm 17$ & $t$-test, $P=0.21$ \\
\hline \multicolumn{4}{|c|}{ Number of people conducting straight leg raising } \\
\hline 1 day & 16 & 26 & $\mathrm{x}^{2}, P=0.025$ \\
\hline 3 days & 20 & 32 & $\mathrm{x}^{2}, P=0.005$ \\
\hline 7 days & 29 & 34 & $\mathrm{x}^{2}, P=0.17$ \\
\hline
\end{tabular}

illustrated that the blood loss consisted of the residual blood in the joint and that extravasation into the tissues was more in group A than in group B. Meanwhile, the foregoing three indexes illustrated that using a tourniquet increases the hidden loss. The flexions achieved at one and three days were significantly better in group B than in group A $(P=$ 0.00 and 0.02 , respectively). The flexion achieved at seven days, however, did not show any significant difference. The number of people who could succeed in conducting straight leg raising at one and three days was also significantly better in group B than in group A $(P=0.025$ and 0.005 , respectively), but not at seven days.

\section{Discussion}

TKA can be associated with a significant blood loss. In order to reduce the intraoperative blood loss, a tourniquet was regularly used in TKA. However, orthopaedic implant procedures differ from more general procedures and bleeding may continue for many hours after completion of the operation and much of this may be occult. The mechanism of the hidden blood loss is generally accepted as the residual blood into the joint, extravasation into the tissues $[6,11]$ and loss due to haemolysis [17]. Extravasation into the tissues can induce limb swelling and subcutaneous ecchymosis. The extent of haemolysis can be evaluated through free haemoglobin concentration.

There are many contradictory publications about the effect of a tourniquet on blood loss following TKA [1, 9, $21,23,24]$. We calculated the hidden blood loss from Tetro et al.'s [21] and Vandenbussche et al.'s [23] experiment results and reached different conclusions: using a tourniquet in TKA increased the hidden blood loss in Tetro et al.'s study and the contrary conclusion was reached in Vandenbussche et al.'s study. Our results are consistent with the study of Tetro and associates. The reason for this may be: Firstly, the ischaemic conditions caused by the use of a tourniquet could induce sustained local reactive hyperaemia, lasting several hours after tourniquet deflation. This would in turn promote more haemorrhage into the traumatised tissue and out of the incision within the postoperative period $[2,10,20]$. Secondly, the increased fibrinolytic activity associated with tourniquet-induced ischaemia promotes bleeding into the local tissues following the procedure $[3,7,10,14]$. Thirdly, the superoxide substances generated in tourniquet-induced ischaemia-reperfusion conditions induces the increased permeability of small vessels, which promotes exosmosis of blood constituents. Fourthly, haemocytolysis could be induced by superoxide substances generated in ischaemia-reperfusion conditions and compression caused by an inflated tourniquet. Fifthly, in this study we deflated the tourniquet after the wound was closed and bandaged, in contrast to the method of releasing the tourniquet before wound closure, and allowing control of bleeding, much more blood flow to the affected limb and increase in the proportion of the hidden blood loss in the total blood loss. Our results contrasted with those of Vandenbussche et al. [23], which might be attributed to the fact that the patients they selected were more difficult and their operating time was much longer than ours.

Appel et al. [4] and Ömeroğlu et al. [15] reported that using a tourniquet could lead to ultrastructural damage of the skeletal muscle distal to the cuff, even rhabdomyolysis, which may be the first step towards muscular atrophy and muscle weakness. In this study, the active knee flexion and straight leg raising activities in the early postoperative 
period in group B were better than in group A, which might be explained by the foregoing. Furthermore, we consider that the swelling of the affected limb caused by the hidden blood loss can also interfere with rehabilitation. The swelling increases the tension of the soft tissue around the knee so as to hinder the knee flexion movement. Meanwhile, the weight of the affected limb also increased, which means that straight leg raising activities need more muscle force. Although the active knee flexion and straight leg raising activities at the seventh postoperative day did not show a significant difference between the two groups, the more effective rehabilitation exercise in the relatively early period should improve the patients' recovery confidence, decrease the incidence of complications lying in bed and improve the patients' satisfaction.

In this study, the percentage of the hidden loss in the calculated total blood loss accounted for $56 \%$ in group A, which differs with the results reported by Sehat et al. [19] and Prasad et al. [16], which were 50 and 38\%, respectively. The reason may be that we did not use a drain in any wound. Mylod et al. [12] reported that using a drain in TKA could effectively relieve haematoma and limb swelling. While without using a drain, instead of leaking out of the body, the blood loss extravasates mostly into the joint cavity and tissue space, which induces limb swelling more obviously and the proportion of the hidden loss in the total loss is much greater. However, the experience in our institute [22] suggests that using a drain in the wound does not reduce the total blood loss and instead interferes with the rehabilitation exercise to some degree in the early postoperative period. So we did not use a drain in this study. In addition, Sehat et al. [19] did not explain the opportunity of releasing the tourniquet in their study. Prasad et al. [16] deflated the tourniquet before wound closure, which means that much more blood flowing to the affected limb only increases the intraoperative blood loss and the hidden blood loss is less than when the tourniquet is released after wound closure. Besides, Rama et al. [18] drew a conclusion through meta-analysis that the total blood loss when the tourniquet is deflated before wound closure is significantly greater than when the tourniquet is deflated after wound closure. Therefore, the proportion of the hidden blood loss as the total loss is lower for these reasons. Furthermore, Sehat et al. [19] did not explain the amount of infusion and whether or not patients received a transfusion. Meanwhile, the occasion of examining the postoperative haematocrit level, which is used to calculate the blood loss, was not explained definitely by Sehat et al. [19]. Prasad et al. [16] calculated the blood loss according to the lowest postoperative haemoglobin concentration, but not the haematocrit level examined at the specific occasion. All these circumstances should be considered when evaluating the difference between the three results.
We concluded that compared with patients undergoing TKA using a tourniquet, when TKA was performed without using a tourniquet the patients can more effectively participate in rehabilitation exercise in a relatively earlier period, which can strengthen the patients' recovery confidence, decrease the incidence of complications associated with immobility and improve the patients' satisfaction.

\section{References}

1. Abdel-Salam A, Eyres KS (1995) Effects of tourniquet during total knee arthroplasty. A prospective randomised study. J Bone Joint Surg Br 77:250-253

2. Authier B (1988) Reactive hyperemia monitored on rat muscle using perfluorocarbons and 19F NMR. Magn Reson Med 8:80-83

3. Aglietti P, Baldini A, Vena LM et al (2000) Effect of tourniquet use on activation of coagulation in total knee replacement. Clin Orthop Relat Res 371:169-177

4. Appell HJ, Glöser S, Duarte JA, Zellner A, Soares JM (1993) Skeletal muscle damage during tourniquet-induced ischaemia. The initial step towards atrophy after orthopaedic surgery? Eur J Appl Physiol Occup Physiol 67:342-347

5. Carson JL, Duff A, Poses RM et al (1996) Effect of anaemia and cardiovascular disease on surgical mortality and morbidity. Lancet 348:1055-1060

6. Erskine JG, Fraser C, Simpson R et al (1981) Blood loss with knee joint replacement. J R Coll Surg Edinb 26:295-297

7. Fahmy NR, Patel DG (1981) Hemostatic changes and postoperative deep-vein thrombosis associated with use of a pneumatic tourniquet. J Bone Joint Surg Am 63:461-465

8. Gross JB (1983) Estimating allowable blood loss: corrected for dilution. Anesthesiology 58:277-280

9. Harvey EJ, Leclerc J, Brooks CE, Burke DL (1997) Effect of tourniquet use on blood loss and incidence of deep vein thrombosis in total knee arthroplasty. J Arthroplasty 12:291-296

10. Klenerman L, Mackie I, Chakrabarti R, Brozovic M, Stirling Y (1977) Changes in haemostatic system after application of a tourniquet. Lancet 1:970-972

11. McManus KT, Velchik MG, Alavi A, Lotke PA (1987) Noninvasive assessment of postoperative bleeding in TKA patients with Tc-99m RNCs. J Nucl Med 28:565-567

12. Mylod AG, France MP, Muser DE et al (1990) Perioperative blood loss associated with total knee arthroplasty. A comparison of procedures performed with and without cementing. J Bone Joint Surg Am 72:1010-1012

13. Nadler SB, Hidalgo JU, Bloch T (1962) Prediction of blood volume in normal human adults. Surgery 51:224-232

14. Nakahara M, Sakahashi H (1967) Effect of application of a tourniquet on bleeding factors in dogs. J Bone Joint Surg Am 49:1345-1351

15. Ömeroğlu H, Erdoğan D, Ömeroğlu S, Günel U, Biçimoğlu A (1997) Ultrastructural analysis of the alterations in skeletal muscle during tourniquet application on extremities (in Turkish). Acta Orthop Traumatol Turc 31:323-326

16. Prasad N, Padmanabhan V, Mullaji A (2007) Blood loss in total knee arthroplasty: an analysis of risk factors. Int Orthop 31:39-44

17. Pattison E, Protheroe K, Pringle RM et al (1973) Reduction in haemoglobin after knee joint surgery. Ann Rheum Dis 32: $582-584$

18. Rama KR, Apsingi S, Poovali S, Jetti A (2007) Timing of tourniquet release in knee arthroplasty. Meta-analysis of randomized, controlled trials. J Bone Joint Surg Am 89:699-705 
19. Sehat KR, Evans RL, Newman JH (2000) How much blood is really lost in total knee arthroplasty? Correct blood loss management should take hidden loss into account. Knee 7: $151-155$

20. Silver R, de la Garza J, Rang M, Koreska J (1986) Limb swelling after release of a tourniquet. Clin Orthop 206:86-89

21. Tetro AM, Rudan JF (2001) The effects of a pneumatic tourniquet on blood loss in total knee arthroplasty. Can J Surg $44: 33-38$
22. Tao K, Wu HS, Li XH et al (2006) The use of a closed-suction drain in total knee arthroplasty: a prospective, randomized study (in Chinese). Zhonghua Wai Ke Za Zhi 44:1111-1115

23. Vandenbussche E, Duranthon LD, Couturier M, Pidhorz L, Augereau B (2002) The effect of tourniquet use in total knee arthroplasty. Int Orthop 26:306-309

24. Wakankar HM, Nicholl JE, Koka R, D’Arcy JC (1999) The tourniquet in total knee arthroplasty. A prospective, randomised study. J Bone Joint Surg Br 81:30-33 